Corresponding Author: GadAllah Modawe;

email:

gadobio77@hotmail.com

Received 26 June 2021

Accepted 03 September 2021

Published 30 September 2021

Production and Hosting by Knowledge E

(c) Maha Fathalla et al.. This article is distributed under the terms of the Creative

Commons Attribution

License, which permits unrestricted use and redistribution provided that the original author and source are credited.

Editor-in-Chief:

Prof. Mohammad A. M. Ibnouf

\section{Evaluation of Serum Gonadotropin and Prolactin Level among Sudanese Patients with Chronic Renal Failure}

\author{
Maha Fathalla1, AbdElkarim A. Abdrabo, and GadAllah Modawe ${ }^{2}$ \\ ${ }^{1}$ Department of Clinical Chemistry, Faculty of Medical Laboratory Sciences, Alneelain University, \\ Khartoum, Sudan \\ ${ }^{2}$ Department of Biochemistry, Faculty of Medicine and Health Sciences, Omdurman Islamic \\ University, Omdurman, Sudan
}

ORCID:

Gad Allah Modawe: https://orcid.org/0000-0003-0536-0614

\section{Abstract}

Background: Generally, patients on hemodialysis for chronic renal failure also have endocrine defects and sexual function disorders. In this study, we aimed to assess the serum prolactin (PRL), luteinizing hormone ( $\mathrm{LH}$ ) and follicle-stimulating hormone (FSH) in patients with chronic renal failure.

Methods: This hospital-based case-control study was conducted at Jabal Aulia Teaching Hospital, Khartoum, Sudan. The study was carried out between August 2019 and February 2020. A total of 100 subjects were enrolled - 50 chronic renal failure patients and 50 as controls. The serum hormones were estimated using Tosoh 360. SPSS version 25 was used to analyze the results.

Results: The serum PRL, LH, and FSH were significantly increased among chronic renal failure patients than their healthy counterparts ( $p$-value $=0.000)$. The age of patients was positive correlated with plasma hormones, PRL ( $r=0.332, p=0.001)$, LH $(r=0.387, p=0.000)$, and FSH $(r=0.320, p=0.001)$. No correlation was found between the duration of the disease and serum hormones.

Conclusion: Patients with chronic renal failure had a highly significant increase of serum PRL, LH, and FSH and also the age of the patients was positively correlated with serum hormones.

Keywords: chronic renal failure, prolactin, gonadotropin, hemodialysis

\section{Introduction}

Patients with chronic kidney disease sometimes experience sexual and gonadal dysfunction, as well as infertility [1]. Reduced libido, erectile dysfunction, premature or delayed ejaculation, and difficulty achieving orgasm are all signs of male sexual dysfunction in renal failure. Whereas reduced libido, trouble achieving orgasm, lack of vaginal lubrication, discomfort during sex, and infertility are all signs of female renal failure 
[2]. With the development of end-stage renal disease, gonad dysfunction worsens. On hemodialysis, up to $40 \%$ of male and $55 \%$ of female patients have trouble achieving orgasm [2]. In patients with chronic renal failure, serum prolactin (PRL) levels and biological activity are both elevated [3]. The increase in serum PRL is related to a decrease in glomerular filtration rate. The primary cause of increased serum PRL levels is decreased dopaminergic inhibition of PRL release from the pituitary gland, followed by decreased luteinizing hormone ( $\mathrm{LH}$ - $\mathrm{RH}$ release. $\mathrm{PRL}$ is a uremic toxin that causes libido loss, erection problems, and infertility. In males, it can cause gynecomastia and galactorrhea, and in females, it can cause menstrual disorders (amenorrhea and oligomenorrhea) and galactorrhea (0-40\% of chronic renal failure $-5 \mathrm{D}$ patients). Thyrotrophic-releasing hormone stimulation decreases PRL production in both men and women [4]. Uremia affects the release of $\mathrm{GnRH}$ and thus gonadotropin production and secretion in both males and females by disrupting local amino acid neurotransmitter outflow in the hypothalamus [5, 6]. Hemodialysis patients have higher follicle-stimulating hormone (FSH) and LH levels in their blood than healthy people. This rise is due to a longer half-life for immune-reactive and -bioactive $\mathrm{LH}$, as well as increased immunoreactive LH secretion [7]. Male and female chronic renal failure patients also suffer from gonadal dysfunction. The purpose of this study was to assess serum PRL, LH, and FSH levels in patients with chronic renal failure.

\section{Materials and Methods}

\subsection{Study population}

This hospital-based case-control study was conducted at Jabal Aulia Teaching Hospital, Khartoum, Sudan. The study was carried out between August 2019 and February 2020. A total of 100 subjects were enrolled - 50 chronic renal failure patients (male 30 [60\%], female 20 [40\%]) with an average age ranging from 18 to 55 years ( $40.46 \pm 9.611$ years) and 50 as controls (male 25 [50\%], female 25 [50\%]) with an average age ranging from 18 to 52 years ( $32.24 \pm 10.024$ years).

\subsection{Inclusion and exclusion criteria}

Patients on hemodialysis for chronic renal failure were included. There were no significant medical complications associated with hemodialysis patients; patients using PRL drugs and those taking anabolizing androgen were excluded. 


\subsection{Data collection and blood sampling}

Data were collected through questionnaire. Blood samples were the serum collected through centrifugation that was drawn from all subjects between 8 and 10 am after an overnight fast and was held at $-20^{\circ} \mathrm{C}$ until assayed. Serum hormones were estimated using Tosoh 360.

\subsection{Statistical analysis}

The Statistical Package for Sciences (SPSS, version 25) was used to perform statistical analysis. Data were expressed as (mean \pm SD) and compared first with controls and then with the provided reference values of the reagents and the data published in the literature. Means of continuous variables were compared between the two groups. $P$ value was computed for hormone levels in the obtained study results. Besides, Pearson's correlation test was applied to predict the correlation of serum hormone with age, duration of disease/years in patients.

\subsection{Ethical consideration}

The study was approved from the Alneelain University, Faculty of Medical Laboratory Sciences.

\section{Results}

TABLE 1: The (mean \pm SD) of serum PRL, LH, FSH and age in the study population.

\begin{tabular}{l|lll} 
Parameters & Patients $(\boldsymbol{n}=\mathbf{5 0})$ & Control $(\boldsymbol{n}=\mathbf{5 0})$ & $\boldsymbol{P}$-value \\
PRL $(\mathbf{n g} / \mathbf{m l})$ & $45.0 \pm 9.7(33.00-68.00)$ & $15.1 \pm 5.1(6.00-25.00)$ & $\mathbf{0 . 0 0 0}$ \\
\hline LH $(\mathbf{m l u} / \mathrm{ml})$ & $84.9 \pm 9.2(70.0-102.0)$ & $29.0 \pm 15.6(6.00-64.00)$ & $\mathbf{0 . 0 0 0}$ \\
FSH $(\mathbf{m l u} / \mathrm{ml})$ & $28.2 \pm 3.2(24.00-38.00)$ & $11.9 \pm 4.05(5.00-19.00)$ & $\mathbf{0 . 0 0 0}$ \\
Age $(\mathbf{y r})$ & $40.4 \pm 9.6(18-55)$ & $32.2 \pm 10.0(18-52)$ & --
\end{tabular}

$n$ : Number; P: Significant difference; LH: Luteinizing hormone; PRL: Prolactin; FSH: Follicle-stimulating hormone; ng: Nongame; ml: milliliter; SD: Standard deviation.

\section{Discussion}

Our study revealed that the serum hormones were increased dramatically in chronic renal failure patients. On the other hand, serum hormones had strong correlation with 
TABLE 2: The (mean \pm SD) of serum PRL, LH and FSH among gender in chronic renal failure.

\begin{tabular}{l|l|l|l} 
Variables & Male $(\boldsymbol{n}=\mathbf{3 0})$ & Female $(\boldsymbol{n}=\mathbf{2 0})$ & $\boldsymbol{P}$-value \\
\hline PRL & $43.3 \pm 9.1(33.00-61.00)$ & $47.5 \pm 10.2(33.00-68.00)$ & 0.144 \\
\hline LH & $85.03 \pm 8.84(72.00-102.00)$ & $84.7 \pm 10.05(70.00-100.00)$ & 0.917 \\
\hline FSH & $28.3 \pm 3.4(24.00-38.00)$ & $28.05 \pm 3.01(24.00-35.00)$ & 0.757
\end{tabular}

$n$ : Number; P: Significant difference; LH: Luteinizing hormone; PRL: Prolactin; FSH: Follicle-stimulating hormone; ng: Nongame; ml: milliliter; SD: Standard deviation.

TABLE 3: Correlations of age and duration with PRL, LH and FSH in chronic renal failure.

\begin{tabular}{ll|l|l|l}
\hline & & PRL & LH & FSH \\
\hline Age $(\mathbf{y r})$ & $\mathrm{R}$ & 0.332 & 0.387 & 0.320 \\
\cline { 2 - 3 } & P-value & 0.001 & 0.000 & 0.001 \\
\hline & $\mathrm{R}$ & 0.079 & 0.172 & 0.100 \\
\hline P-value & 0.587 & 0.232 & 0.491
\end{tabular}

LH: Luteinizing hormone; PRL: Prolactin; FSH: Follicle-stimulating hormone; R: Correlation.

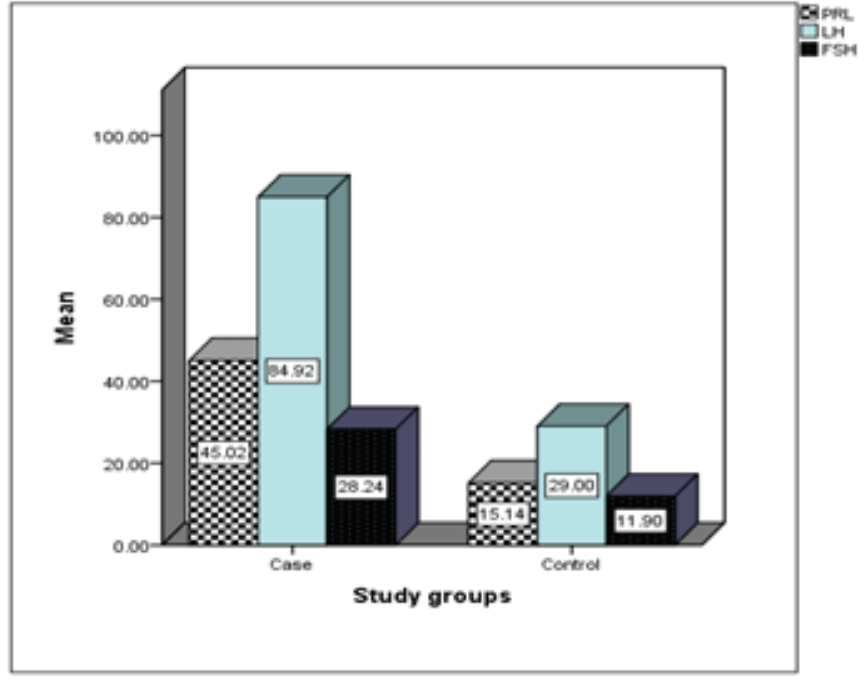

Figure 1: Means of serum PRL, LH, and FSH in study population.

elderly patients. The association between renal failure disease with sex hormones has been examined in several previous studies [8,9]. Hyperprolactinemia is likely a contributing to factor in chronic renal failure due to its atherosclerotic process [10]. Increased expression of PRL receptors has been found in human atherosclerotic plaques and may be a contributing factor to vascular derangements per sec [10, 11]. The age group of study population was supported by Highlander and Lehtihet's study [12]. Our study agrees with the finding of Nihal et al. [13] and report the elevation of serum, PRL, LH. The hypothalamic-pituitary axis in chronic renal failure is reset in such a way that it is more susceptible to the negative feedback inhibition of testosterone, and the regulation of gonadotropin secretion is impaired [14]. The significant reduction (70\%) in renal filtration and whole body clearance rate of $\mathrm{LH}$ could also be due to a factor in 


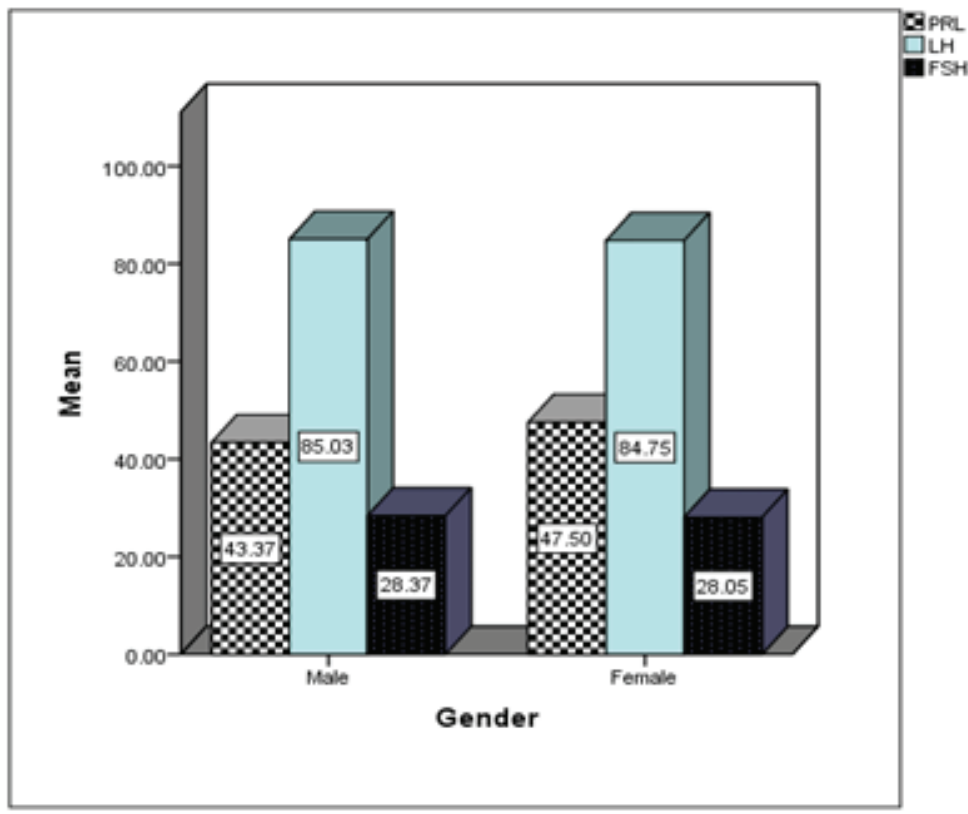

Figure 2: Means of serum PRL, LH, and FSH among gender in chronic renal failure.

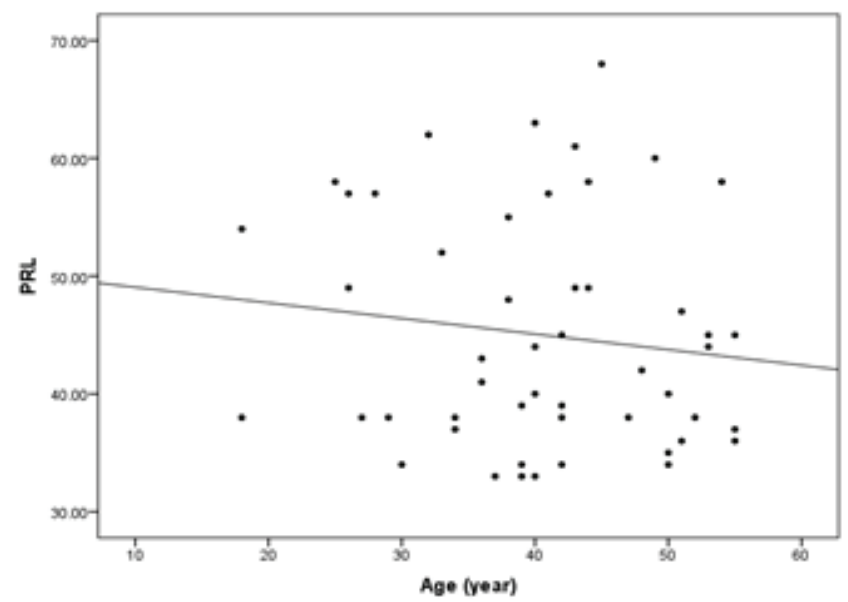

Figure 3: Correlation of age with prolactin in case group $(R=0.332, P=0.001)$.

uremic serum capable of blocking the LH receptor [15]. Our results similar to that found by Mohammed and Amar (2019) registered that hyperprolactinemia exists in renal failure patients. Sobki et al. (2004) reported that the levels of FSH and LH were significantly increased in Saudi male patients on hemodialysis. Early renal insufficiency is associated with elevated LH levels, which increase with declining renal function [18]. Moreover, levels of inhibin and gonadal hormone reflect to, are interested in the input of pituitary gonadal hormone levels and the functional state of the seminiferous epithelium [19]. Our findings contradict a Sudanese study conducted in Khartoum state, which found no substantial differences in patient key PRL levels when compared to the control 


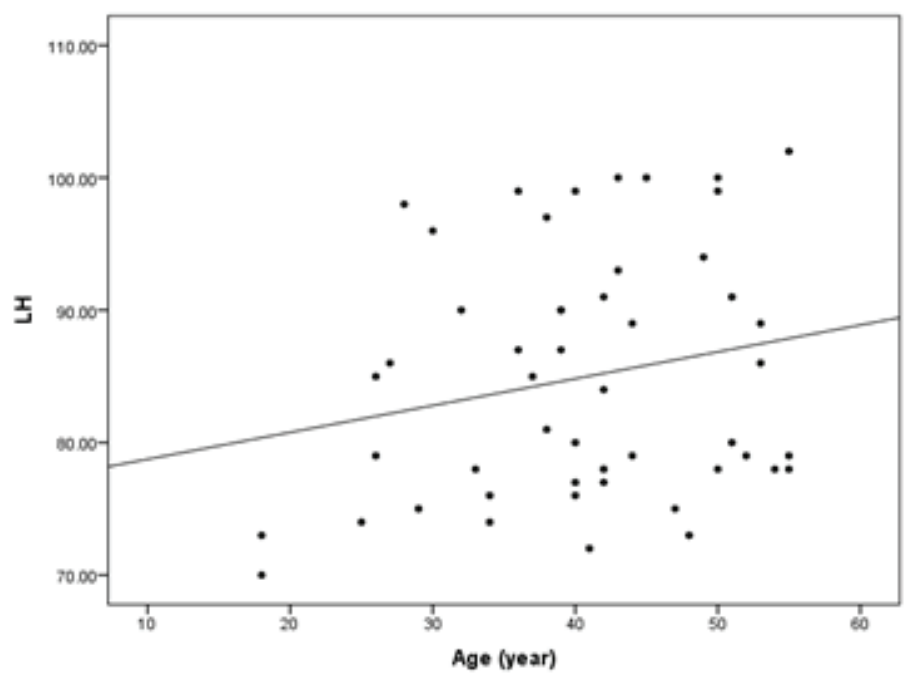

Figure 4: Correlation of age with LH in case group $(R=0.387, P=0.000)$.

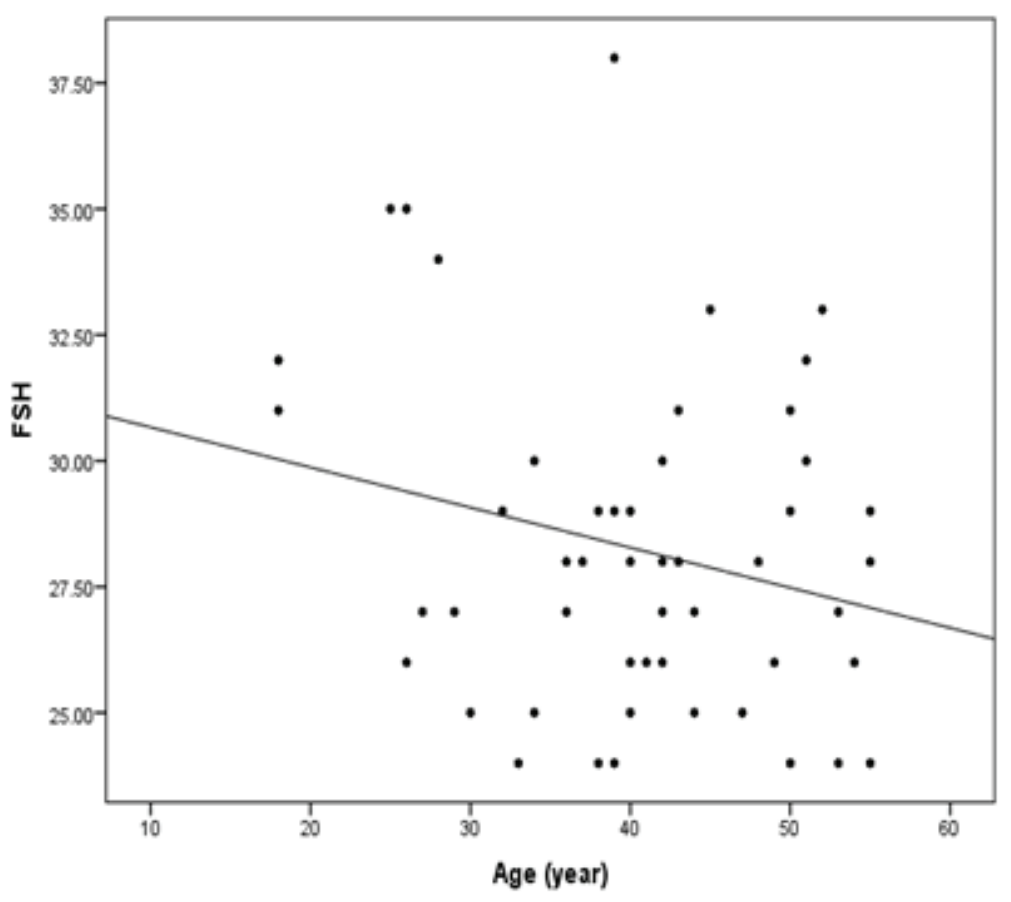

Figure 5: Correlation of age with FSH in case group $(R=0.320, P=0.001)$.

group, implying that hyperprolactinemia exists in renal failure patients [20]. Another research found that CKD is linked to higher levels of the hormone PRL in the blood (hyperprolactinemia) [21]. 


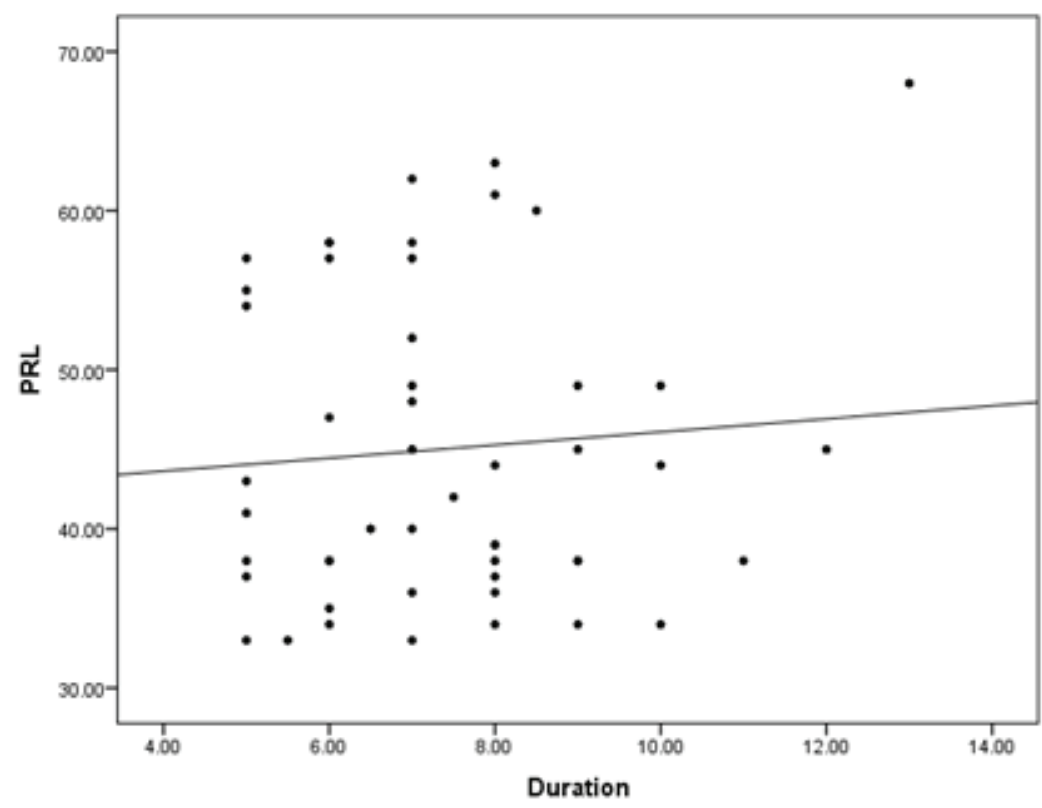

Figure 6: Correlation of duration with PRL in case group $(R=0.079, P=0.587)$.

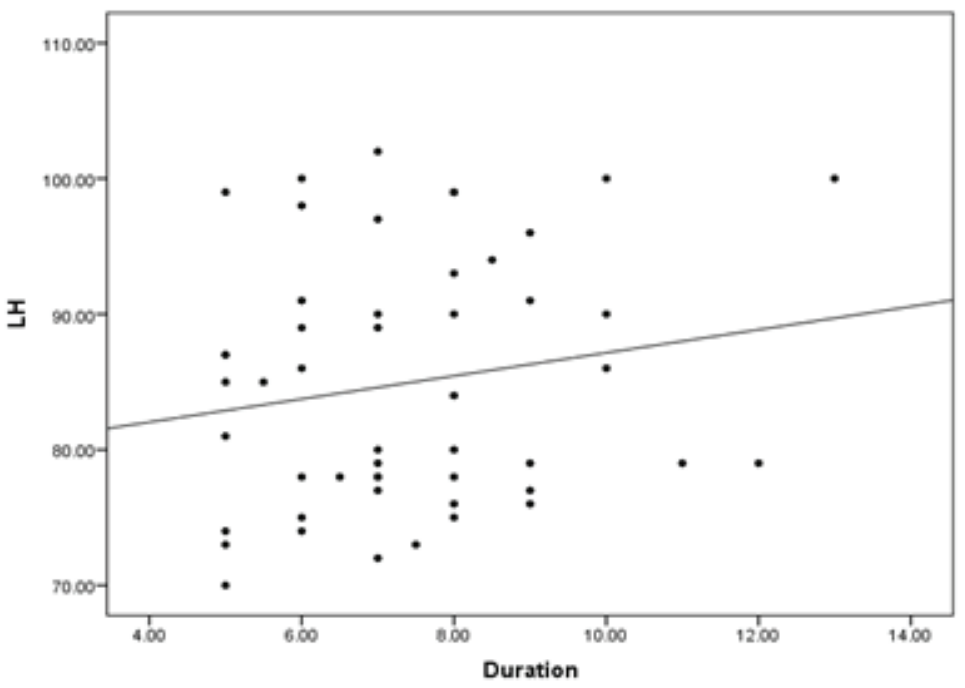

Figure 7: Correlation of duration with LH in case group $(R=0.172, P=0.232)$.

\section{Conclusion}

Patients with chronic renal failure had a highly significantly increase of serum PRL, LH, and FSH. Also, the age of patients had a positive correlation with serum hormones. 


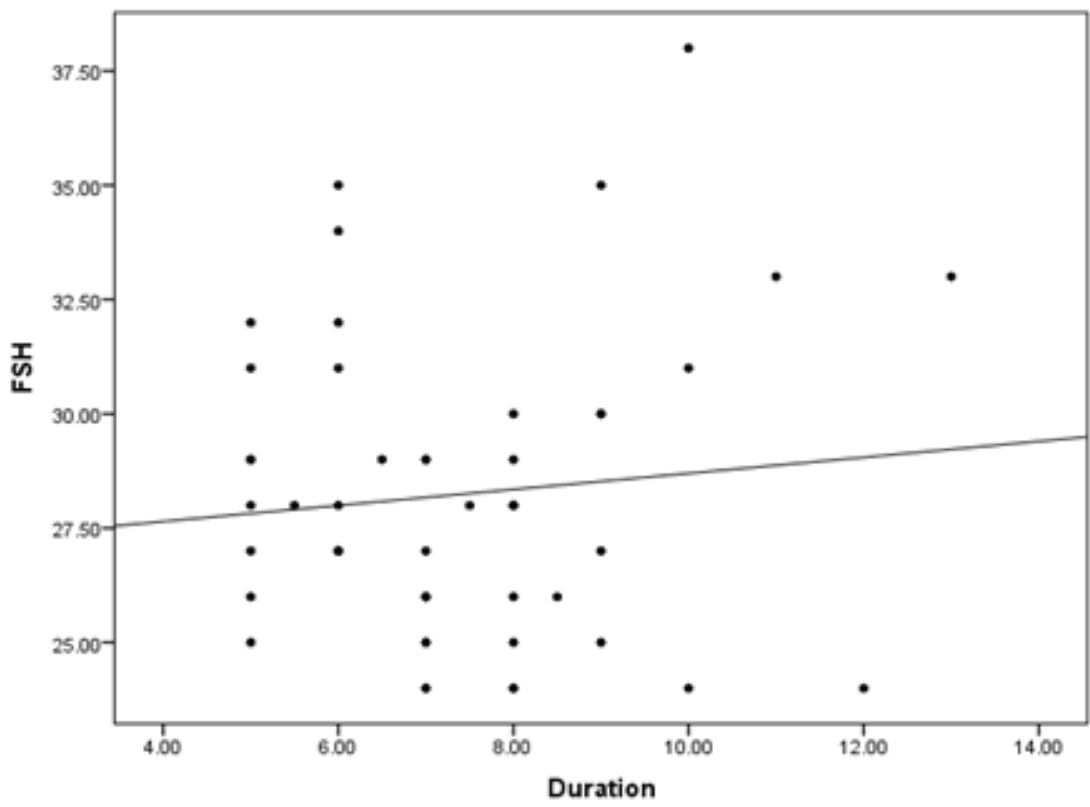

Figure 8: Correlation of duration with FSH in case group $(R=0.100, P=0.491)$.

\section{Acknowledgements}

The authors would like to thank the members of the Department of Clinical Chemistry, their colleagues, and the staff workers at the medical laboratory of Alneelain University for their contribution and support.

\section{Ethical Considerations}

This study has been approved by the Faculty of Medical Laboratory Sciences review board, Alneelain University.

\section{Competing Interests}

None declared.

\section{Availability of Data and Material}

All data and materials associated with this paper were available through the corresponding author upon reasonable request. 


\section{Funding}

None.

\section{References}

[1] Rathi, M. and Ramachandran, R. (2012). Sexual and gonadal dysfunction in chronic kidney disease: pathophysiology. Indian Journal of Endocrinology and Metabolism, vol. 16, no. 2, pp. 214-219.

[2] Finkelstein, S. H. and Finkelstein, F. O. (2002). Evaluation of sexual dysfunction in dialysis patients. In A. R. Nissenson and R. N. Fine (Eds), Dialysis therapy ( $3^{\text {rd }}$ ed., pp. 368-373). Philadelphia: Hanley and Belfus.

[3] Biasioli, S., Mazzali, A., Foroni, R., et al. (1988). Chronobiological variations of prolactin (PRL) in chronic renal failure (CRF). Clinical Nephrology, vol. 30, pp. 86-92.

[4] Bommer, J., Ritz, E., del Pozo, E., et al. (1979). Improved sexual function in male haemodialysis patients on bromocriptine. Lancet, vol. 2, no. 8141, pp. 496-497.

[5] Schaefer, F., Vogel, M., Kerkhoff, G., et al. (2001). Experimental uraemia affects hypothalamic amino acidneurotransmitter milieu. Journal of the American Society of Nephrology, vol. 12, no. 6, pp. 1218-1227.

[6] Schaefer, F., van Kaick, B., Veldhuis, J. D., et al. (1994). Changes in the kinetics and biopotency of luteinizing hormone in hemodialyzed men during treatment with recombinant human erythropoietin. Journal of the American Society of Nephrology, vol. 5, no. 5, pp. 1208-1215.

[7] Schaefer, F., Veldhuis, J. D., Robertson, W. R., et al. (1994). Immunoreactive and bioactive luteinizing hormone in pubertal patients with chronic renal failure. Kidney International, vol. 45, no. 5, pp. 1465-1476.

[8] Yilmaz, M. I., Sonmez, A., Qureshi, A. R., et al. (2011). Endogenous testosterone, endothelial dysfunction, and cardiovascular events in men with nondialysis chronic kidney disease. Clinical Journal of the American Society of Nephrology, vol. 6, no. 7, pp. 1617-1625.

[9] Dunkel, L., Raivio, T., Laine, J., et al. (1997). Circulating luteinizing hormone receptor inhibitor(s) in boys with chronic renal failure. Kidney International, vol. 51, no. 3, pp. 777-784

[10] Carrero, J. J., Kyriazis, J., Sonmez, A., et al. (2012). Prolactin levels, endothelial dysfunction, and the risk of cardiovascular events and mortality in patients with CKD. Clinical Journal of the American Society of Nephrology, vol. 7, no. 2, pp. 207-215. 
[11] Reuwer, A. Q., Twickler, M. T., Hutten, B. A., et al. (2009). Prolactin levels and the risk of future coronary artery disease in apparently healthy men and women. Circulation. Cardiovascular Genetics, vol. 2, no. 4, pp. 389-395.

[12] Hylander, B. and Lehtihet, M. (2015). Testosterone and gonadotropins but not SHBG vary with CKD stages in young and middle aged men. Basic and Clinical Andrology, vol. 25 , p. 9.

[13] El-Assaly, N. M., El-Ashry, N. I., Waked, E., et al. (2008). Gonadal dysfunction in chronic renal failure. Australian Journal of Basic and Applied Sciences, vol. 2, no. 3, pp. $481-487$.

[14] Handelsman, D. J. (1985). Hypothalamic-pituitary gonadal dysfunction in renal failure, dialysis and renal transplantation. Endocrine Reviews, vol. 6, no. 2, pp. 151-182.

[15] Dunkel, L., Raivio, T., Laine, J., et al. (1997). Circulating luteinizing hormone receptor inhibitor(s) in boys with chronic renal failure. Kidney International, vol. 51, no. 3, pp. 777-784.

[16] Adam, M. Y. M. and Ismail, A. M. (2019). Assessment of prolactin level among chronic renal failure patients in Khartoum State. Pathology and Laboratory Medicine, vol. 3, no. 1, pp. 1-4.

[17] Sobki, S. H., Al-Etah, H., El Gezeery, A., et al. (2004). Effect of age on pituitary gonadal hormonal responses in HD patients. Saudi Journal of Kidney Disease and Transplantation, vol. 15, no. 4, pp. 447-454.

[18] Wu, S. C., Lin, S. L., and Jeng, F. R. (2001). Influence of erythropoietin treatment on gonadotropic hormone levels and sexual function in male uremic patients. Scandinavian Journal of Urology and Nephrology, vol. 35, no. 2, pp. 136-140.

[19] Meachem, S. J., Nieschlag, E., and Simoni, M. (2001). Inhibin B in male reproduction: pathophysiology and clinical relevance. European Journal of Endocrinology, vol. 145, no. 5, pp. 561-571.

[20] Adam, M. Y. M. and Ismail A. M. (2019). Assessment of prolactin level among chronic renal failure patients in Khartoum State. Pathology and Laboratory Medicine, vol. 3, no. 1, pp. 1-4.

[21] Nehru, D., Kandasamy S, Chandrmouli, R. K., et al. (2016). Evaluation of serum prolactin level in chronic renal failure. Asian Journal of Pharmaceutical and Clinical Research, vol 9, no. 4, pp. 201-203. 